Published as: Azadi, H., Verheijke, G. \& Witlox, F. (2011), Pollute first,

\title{
Pollute first, clean up later?
}

\author{
Hossein Azadi $^{\mathrm{a}}$, Gijs Verheijke ${ }^{\mathrm{b}}$, Frank Witlox ${ }^{\mathrm{a}}$ \\ ${ }^{a}$ Department of Geography, Ghent University, Belgium \\ ${ }^{b}$ Department of Life Science and Technology, Faculty of Life Sciences, \\ University of Groningen, The Netherlands
}

10 Abstract

11 There is a growing concern with regard to sustainability in emerging economies like

12 China. The Chinese growth is characterized by a strategy which is known as "pollute first,

13 clean up later". Here we show that based on this strategy, the pollution alarm can often be

14 postponed by a tremendous economic growth that can potentially improve welfare and

15 educational systems. The welfare and educated societies will be aware and rich enough

16 not only to clean up but also to prevent the environmental pollutions. It underlines that a

17 certain threshold of development should first be reached before a society is capable of

18 understanding the adverse effects of large scale pollution. For this purpose, we need to

19 encourage the use of fossil fuels in the first place. The challenge however remains to

20 make sure whether such a strategy can develop in a sustainable way.

21 Keywords: Pollution, economic growth, emerging economies, global warming, GHG,

22 sustainability.

\footnotetext{
${ }^{1}$ Corresponding author. Email: hossein.azadi@ugent.be, Tel. +32 (0)9 2644695 . Fax +32 (0)9 2644985
} 


\section{1. Introduction}

24 What would happen if China would match North American consumption habits overnight?

25 A popular statement expressing justified worries about the sustainability of Western

26 lifestyles and Western economic growth. The last decade has seen record breaking

27 temperature maxima (Parker et al., 1994; Jones et al., 1999; IPCC, 2001), unparalleled

28 atmosphere CO2 levels (Song, 2006), and some of the most devastating hurricanes in

29 centuries (IPCC, 2001). Luckily, things are getting better. Greening and sustainability are

30 the buzz words of the $21^{\text {st }}$ century. Nuclear energy is revisited in many places. The Dutch

31 no longer have a monopoly on harnessing wind energy for production means. The rapidly

32 growing economies of the BRIC countries (Brazil, India and China) and the Asian Tigers

33 are spending considerable time and money on greening and sustainability. The Chinese

34 are said to be employing a strategy of "pollute first, clean up later". Obviously, the West

35 has followed exactly the same development pattern. In the 1950's when the Western

36 industry was booming, adverse effects of pollution were not yet known. It is often said

37 that we should try to make the underdeveloped countries in "leapfrog" over the polluting

38 stages of industrial development (Chen, 2004). Unfortunately, that is virtually impossible

39 for a variety of reasons. The challenge for the West is making knowledge about

40 sustainable growth and the technology to attain it available to countries on the verge of

41 industrialization. This way, the cleaning up will start significantly earlier than it did in the

42 West and in China. The hypothesis that will be tested in this paper is that for a country to

43 realize there is a need for pollution mitigation, a certain threshold of development must

44 first be reached. This makes "pollute first, clean up later" an unavoidable development 45 pathway. 
46 In this paper, there will be frequent mention of the terms "Western World" and

47 "industrialization". It is important to note that the former is intended to signify countries

48 with similar development situations while the latter highlights "modernization theory"

49 with regard to the former that besides Europe and the USA, also includes Australia, New

50 Zealand and Japan (the Asian Tigers ${ }^{2}$ are named separately because they developed

51 significantly later than the Western countries). The Western industrialization pathway is

52 explained historically by "modernization theory" which encourages massive production

53 (and consumption) through high technological use and improvement in organizational

54 management. Although the theory has been explicitly used as guides for emerging

55 economies (such as China; see: Qian, 2009), given the importance of the pollution alarms

56 as regarded in this paper, our notion goes beyond modernization and somewhat touches

57 "post-modernization". In other words, the industrialization pathway of emerging

58 economies encourages massive production while does not neglect the 'pollution' impacts,

59 but suggests that the 'clean up' stage might be postponed by a tremendous economic

60 growth.

61 In the first part of this contribution, a summary of the most important views on global

62 warming is given. The widespread belief that pollution at its current rate will produce

63 catastrophic climate change is challenged by substantial criticism. $\mathrm{CO} 2$ emission is

64 projected to cause major global temperature rises. This global warming effect is thought

65 to subsequently cause more acute drought in dry areas, higher intensity of rainfall in wet

66 areas, higher hurricane frequency and even a new ice age as a result of catastrophic

\footnotetext{
${ }^{2}$ Here limited to Hong Kong, Singapore, South Korea and Taiwan. Some authors include Japan as well. However, since Japan developed decades before the other Tigers, from an economical point of view, it might be better qualified as a Western country.
} 
67 changes in hot and cold gulf streams. The scientific basis for these apocalyptic 68 projections is questionable. The models using predictions are biased to special

69 measurements and may neglect some other important parameters which we may not even

70 know because the climate is such a complex system. Moreover, the models are often

71 based on questionable presumptions that have not been proved truthfully. Skeptics face

72 similar problems in making their points. The main problem is that large scale pollution is

73 such a recent challenge, that the amount of available data is simply not sufficient to make

74 any definite judgments and claims about links between pollution and global warming.

75 The above-mentioned argument will be followed by the link between education and

76 development. Does development result from education? Or does it precede education?

77 We will discuss that development and education are intertwined and follow a predictable

78 pattern in selected historic cases. Generally, a more intelligent population that results

79 from a well developed education system has strong effects on society. It significantly

80 encourages the population to read newspapers and watch the news. Nationwide

81 distribution of information on every conceivable subject is no longer a problem. The

82 government and/or NGOs can use this information network to teach society about the

83 adverse effects of pollution. The process of cleaning up can then begin. Finally, it is

84 stressed that limitless pollution is not promoted here. The West has a responsibility to set

85 the example for developing countries. Only then cleaning up can be fast and growth can

86 be sustained.

\section{2. Believers and skeptics on pollution forced global warming}

88 From a political point of view, the theory of anthropogenic global warming has prevailed 89 over the skeptics. One of the publically well known events showing this is the public's 
90 reaction after the release of Al Gore's “An Inconvenient Truth” (2006) and Martin

91 Durkin's "The Great Global Warming Swindle" (2007). The first was met with

92 worldwide praise while the second was surrounded with controversy. As in every

93 politically sensitive debate, information is often being misrepresented on both sides,

94 research is manipulated and the significance of data is being grossly exaggerated. Various

95 studies have proved that we are in fact breaking temperature records and that

96 atmosphere's $\mathrm{CO} 2$ has been steeply rising since mid $20^{\text {th }}$ century. However it has also

97 been shown that climate prediction models do not hold in the face of reality and that the

98 apocalyptic predictions of climate change activists are out of proportion. In this section,

99 an attempt is made to filter science out of the political fog. The most important arguments

100 pro and con anthropogenic global warming are summarized, as this is an important basis

101 to understand the argument to promote $\mathrm{CO} 2$ emission in developing countries.

102 Since the start of temperature data registration in 1880, the global earth surface air

103 temperature has risen by $\sim 0.6^{\circ} \mathrm{C}$ (Parker et al., 1994; Jones et al., 1999; IPCC, 2001).

104 Estimations from ice core data suggest that average global CO2 concentrations have

105 always been below 300ppm before 1880. Direct measurements since the late 1950's

106 shows that in the $20^{\text {th }}$ century, $\mathrm{CO} 2$ concentration has dramatically increased from

$107315 \mathrm{ppm}$ in 1958 to 375ppm in 2004 (Song, 2006). There is no doubt that this recent rise

108 in $\mathrm{CO} 2$ concentration is being caused by human interventions mainly the industrial use of

109 fossil fuels. It is also unquestionable that increasing the concentration of a known

110 greenhouse gas by 25 percent in a 100 year time span is undesirable and will most likely

111 have an effect on the earth's climate. 
112 According to climate specialists at IPCC the icecaps at the North Pole have shrunk

113 considerably and various glaciers have melted. In recent years, we have seen an increase

114 of drought in dry zones and an increase of precipitation in wet areas. Record breaking

115 annual hurricane rates have been reached in recent years. These are mostly paraphrased

116 excerpts from the IPCC report 2001. While the IPCC reports are backed by an impressive

117 amount of well known scientists, it is sometimes hard to find out where their data is

118 coming from. Moreover, some studies have for example shown a dramatic increase in

119 hurricane prevalence between 1988 and 1989 (Asimov and Pohl, 1993), while failing to

120 take into account that hurricane prevalence has fallen back to historically very low rates

121 after that two-year period. B. Lomborg has pointed out an impressive amount of this type

122 of scientific errors and exaggerations - including the aforementioned example on

123 hurricanes - in his 2001 book titled "The Skeptical Environmentalist". Lomborg refers to

124 the widespread belief that humans are the worst thing that has ever happened to the planet

125 as "The Litany". It has been - and still is - repeated so many times that people start taking

126 it for granted, enabling scientists to make claims such as:

127 Intensity of precipitation events is projected to increase, particularly in tropical and high 128 latitude areas that experience increases in mean precipitation. Even in areas where mean 129 precipitation decreases (most subtropical and mid-latitude regions), precipitation intensity is 130 projected to increase but there would be longer periods between rainfall events. There is a 131 tendency for drying of the mid-continental areas during summer, indicating a greater risk of 132 droughts in those regions. Precipitation extremes increase more than does the mean in most 133 tropical and mid- and high-latitude areas. (IPCC, 2007; Chapter 10, p4) 
135 This is just one example. The IPCC reports are characterized by intricate causality claims

136 and projections without any reference to research data or even academic literature

137 proving them. However, few people notice this because in current Western society these

138 apocalyptic claims are so often repeated that they seem undisputable.

139 Predictions for future climate change and the implications this has for life on earth are

140 based on complicated mathematical climate models. The climate is so complex however,

141 that the models are far from complete. This is recognized by the people using them, but it

142 is argued that the models are complete enough to predict the direction and overall

143 magnitude of climate change in the future. In this respect it is interesting to note that the

144 bursting of the US housing bubble resulted in the global financial crisis of $2007-2009$

145 largely because asset pricing based on mathematical models turned out to be completely

146 detached from reality.

147 The environmental activists' argument can always fall back to in the face of scientific

148 criticism saying the "better safe than sorry". This seems the only completely waterproof

149 argument promoting mitigation. It combats the fact that the 50 years of reliable direct

$150 \mathrm{CO} 2$ concentration measurement is simply not enough to know what percentage of the

151 concentration rise is anthropogenic or what affects a higher $\mathrm{CO} 2$ concentration will have

152 on the world around us. However, industry looks and smells bad, it is known to emit CO2,

153 and it is a fact that atmosphere $\mathrm{CO} 2$ concentration is rapidly rising. It is therefore a good

154 idea to mitigate pollution until the consequences are better understood just in case they

155 do turn out to be as apocalyptic as environmentalists claim.

156 Global warming critics primarily aim at exposing vulnerabilities in the scientific basis

157 behind pollution forced global warming. They have been fairly successful in finding them, 
158 but have difficulty in gaining political acceptance for their views. The critics point out

159 that it has not been possible to link the rise in $\mathrm{CO} 2$ concentration to the temperature rise.

160 From ice core data, it is possible to show temperature following $\mathrm{CO} 2$ concentration. It is

161 however, equally possible to show $\mathrm{CO} 2$ concentration following temperature.

162 Furthermore, critics argue that while a portion of the rising global temperature can

163 probably be attributed to human action, it is highly likely that we are presently in a period

164 of natural global warming as well. Some writers have used various methods of statistical

165 curve fitting to make data fit their hypotheses stating a causal relationship between $\mathrm{CO} 2$

166 and temperature (Gilliland, 1982; Hansen et al., 1981).

167 The notion that climate change is an undesirable thing can also be disputed. As a result of

168 global warming, the climate is projected to become warmer and wetter (IPCC, 2007), in

169 effect creating conditions far better suited to general life on earth. The hot and humid rain

170 forests of South America and Southeast Asia have a far larger variation of animal species

171 than the colder parts of Europe for example. NGOs however, tend to focus on individual

172 animals, preferably with high attractive qualities in the public's eyes. A strong case could

173 be made to argue that the Giant Panda is so unfit for its environment that it should have

174 been extinct for decades. Does the cute way a penguin walks or the fearful facial

175 expression of a drowning polar bear make climate change a terrible crime? It certainly

176 helps to make people believe so. This line of reasoning is a key in the main opposition for

177 the "better safe than sorry" argument. This is what could be respected as "nature always

178 finds its way" argument. Species rise and fall by nature. Even if temperature rises by 10

179 full degrees it is unlikely that life on earth will be unable to adapt. It is hard to predict

180 what such a world would look like, and it is questionable if we should desire to pursue it. 
181 Additionally, it is simply a delusion of grandeur to think that we, as humans, have the

182 power to destroy the earth by burning some coal.

183 Critics have further argued that in the period between 1945 and 1975, global temperature

184 was decreasing rather than increasing, causing some of the first environmental scientists

185 to warn against the dawning of a new ice-age. This cooling has later been contributed to

186 the increased prevalence of clouds caused by emission of sulphate aerosols (Plambeck et

187 al., 1997). Skeptics have furthermore tried to make a case based on the idea that global

188 warming is not forced by $\mathrm{CO} 2$ emission but by solar activity variation. However, "while

189 many positive correlations between solar variations and climate changes are impressive,

190 this subject remains controversial because they switched in some cases abruptly to

191 anticorrelations." (Bucha, 1991; p. 2).

192 In sum, most scientific researchers either presume that $\mathrm{CO} 2$ is causing global warming,

193 or focus on trying to prove these researchers are wrong. The first can simply not be

194 proved at this point and the latter lacks constructive conclusions.

195 There is one more interesting take on $\mathrm{CO} 2$ effects from research on vegetation. The thesis

196 is that the process of photosynthesis has evolved in an atmosphere where CO2

197 concentration was far higher than today. As a result, most plants operate at suboptimal

198 levels and hence would benefit from elevated CO2 concentration. This has been shown in

199 Dutch potatoes (Wolf and Van Oijen, 2003), wheat (Manderscheid et al., 2003) and

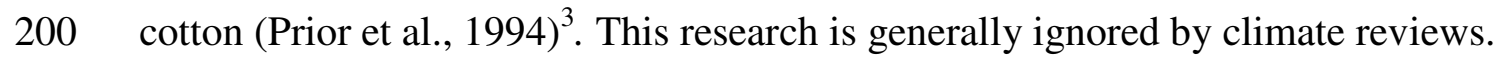

201 Overall, both temperature and $\mathrm{CO} 2$ concentration show clear rising trends since the start

202 of the $20^{\text {th }}$ century. The assumption that temperature rise is caused by CO2 elevation is

\footnotetext{
${ }^{3}$ There are also studies showing that elevated $\mathrm{CO} 2$ levels do not have a profound effect on crop yields. The consensus is that $\mathrm{CO} 2$ enrichment favors crop yields anyhow.
} 
203 far to prove by current methods and with available data. This means we have no scientific

204 evidence for the belief that the climate will stop warming if we stop emitting CO2.

205 Moreover, the door is being firmly held shut against the possibility of positive effects of a

206 warmer climate and CO2 concentration elevation.

207

208 
210 The developed countries in the west are characterized by a high level of general

211 education. In most of these countries, schooling is even obligatory and entirely paid for

212 by the government up to a certain age. Is this a result of high development, or is it the

213 other way around?

214 Industrialization in the $19^{\text {th }}$ century was driven by the excess of capital that resulted from 215 technological improvements in agriculture. Farmers grew certain crops for cash to invest

216 in more advanced technology for their farms. To facilitate trade between cities high

217 capacity infrastructure was necessary. This resulted in steam engine technology from

218 ships being implemented in railway transport. With the turn of the century we saw the

219 invention of cars and airplanes. Less than a decade later, both of these inventions were

220 already being mass produced. Factory work was complex and it was a huge advantage if

221 workers were able to read instructional manuals. So, education had become a necessity.

222 Up to the mid $19^{\text {th }}$ century, Europe and North America were still mostly rural economies.

223 Farmers and craftsmen like carpenters and blacksmiths were mostly home educated. They

224 learned a trade, which was often passed on from father to son. A blacksmith or potato

225 farmer had no use for literacy. When industrialization caught on, with any advancement

226 in technology, work in the factories got more complex. It was quickly realized that

227 workers needed to have some basic education to understand what they were doing. This

228 is pointed out in Chinese development during and after the Cultural Revolution.

229 China's achievements in basic education, especially before and during the Cultural

230 Revolution, have contributed significantly to her economic growth thereafter. The subsequent 231 expansion of junior, secondary, technical and higher education from 1978 has enabled China 
235 This quote shows that the need for smarter general public is not limited just to the

236 workforce. The elite badly needed expansion as well. Higher education institutes teaching

237 economics, management and engineering rocketed. It was no longer the doctors and

238 lawyers who made the money but industrial entrepreneurs. In Forbes magazine's list of

239 richest people ever, 14 out of 75 persons included are Americans born between 1830 and

240 1840. All renowned American business schools were founded between 1880 and 1920

241 (Gladwell, 2008).

242 The strong link between education and economic development has already been proved

243 in 1982 (Colclough, 1982). Primary schooling increases labor productivity in rural and in 244 urban sectors.

245 A good example of the link between education and economic development is the 246 situation in Eastern Europe. During the Soviet period, the Soviet Union was considered

247 an important world power. Industrialization was rapid and successful, primarily regarding

248 military products. School enrollment rates followed a rising trend, as in every industrial

249 country. After the fall of the Soviet Union in the 1980's however, school enrollment rates

250 started to fall. In 1985, educational expansion showed clear downward movement in

251 Russia, Slovakia and Hungary (Ganzeboom and Nieuwbeerta, 1999). Poland was the only

252 country studied where education enrollment kept rising. Today, Poland is one of the more

253 developed Eastern European states. Russia, in the mean while, has one of the largest gaps

254 between rich and poor in the world and could be considered to be de-developing in 255 several ways. Education can clearly be a result of economic growth. It can obviously 
256 increase growth as well. In a true answer of the "hen or egg" question; neither

257 development, nor education definitely comes first. Economies evolve more gradually and

258 each results from the other. A general pattern can be seen however. Clearly, a first

259 necessity is a stable political situation. After that, educated elite is needed to force

260 technological innovation and industrialization. As a result of the rapid growth associated

261 with industrial growth, more and more of ever more complicated work becomes available.

262 A significant part of the excess capital resulting from the rapid growth is subsequently

263 invested in educating a blue collar workforce to operate complicated machinery and hold

264 lower and middle management function. Some of these newly educated people will later

265 start their own industries or service sector businesses. Industrial development could be

266 said to jumpstart a virtuous cycle of development, resulting in higher need for education,

267 in turn resulting in more, faster and different development.

268 As a result, such "educated and rich" societies can not only understand the consequences

269 of their developmental interventions in the environment but also they are now rich

270 enough to take some concrete actions to forbid and close those industries which are

271 processing and creating some outputs against the environment and replace them with

272 some new environmentally-friendly businesses. To make enough empathy with the

273 environment, therefore, they have both the "knowledge" and "capital" which have been

274 resulted from economic growth that may already cause some pollution in the environment.

276 3.1. Education in developing countries

277 In Latin America, Africa and most of Asia, education levels were very low after World

278 War II. Colonists had no interest in developing education systems for the native 
279 inhabitants of their colonies (Heinink and Koetsier, 1984). Some native elites were 280 trained to fulfill administrative positions in the colonial country (Szirmai, 2005, p228).

281 These people were educated in the language of the colonial force and curriculums were

282 based on Western education. The mass was however not admitted to any substantial

283 education, other than some practical lessons on how to run their farms. The non-

284 colonized countries such as China and Thailand had little traditional education system

285 after World War II as well. They just completely missed the development bandwagon in

286 the $19^{\text {th }}$ century. This is probably because these countries were never a subject to any

287 serious outside force promoting development. While European countries were fighting

288 each other for as long as we can trace history, China has mostly had a very "introverted"

289 civilization. Europe, and later the USA were in an innovations race since the 1600's,

290 ultimately resulting in the industrial revolution and mass education of the late $19^{\text {th }}$ and

291 early $20^{\text {th }}$ centuries. A notable case is provided by the Asian Tigers. The Tigers have

292 completely caught up with the Western world, even though their industrial development

293 started as late as the 1960's. Singapore and Hong Kong are among the most important

294 financial centers in the world (Financial Times, November $3^{\text {rd }}, 2009$ ). Since the early

2951980 's, capital growth rate in Taiwan has risen from 10\% to more than 20\% per year (Lin,

296 2004). Lin also shows that a one percent rise in higher education stock ${ }^{4}$ results in

297 approximately $0.19 \%$ increase in real output. In another article Lin states that in 1968,

298 government started a policy in which all youths were obligated to attend nine years of

299 education (Lin, 2003). This was preceded however, by efforts of the Japanese colonial

\footnotetext{
${ }^{4}$ The percentage of people who received higher education (junior college, college, university or graduate school).
} 
300 force in the 1940's to industrialize Taiwan. Again, the same pattern of industrialization,

301 emergence of higher education and subsequent rapid economic development is followed.

\subsection{Implications of education for the environmental movement}

304 As thus far discussed, the complicated nature of work in an industrial country requires an

305 educated workforce. The resulting higher general level of education has profound effects

306 on society. The acceleration of development is also a direct effect of education but there

307 are other, more hidden consequences of an educated population. External effects of

308 education are reduced fertility and higher infant health (Lloyd et al., 2000). The most

309 important effect however is the increased general intelligence of society. In the developed

310 world we know that we should try to cut back on pollution because we are taught so in

311 school. Knowledge is passed on, and more importantly, expanded on from generation to

312 generation. When it became clear that industry might have adverse effects on the

313 environment, science directed attention toward proving this hypothesis. This gave rise to

314 the first scientific approaches to environmental science. The cooling of the earth between

3151945 and 1975 made scientists fear a new ice age was dawning. In school, we are taught

316 to trust scientists, the news and politicians. If we had not received basic education, we

317 would not even be able to understand the newspapers. That is the situation in most of

318 Africa and large illiterate parts of Asia. People in remote rural areas receive little national

319 news and general knowledge is very low. They are literally decades behind in

320 development. This gives rise to situations such as one in Southwest Iran where some

321 small scale farmers believe pesticides are so inactive currently that they could even dare

322 to drink them! They failed to realize that the chemicals were not inactive, but the pests 
323 became more resistant to them ${ }^{5}$. The point is that basic education is a precondition for

324 people to be able to understand that the pollution has effects on the environment.

325 Otherwise, people are unable to relate to the concept of greening now to guarantee a safe

326 future for their grandchildren. The intrinsic egocentric attitude of all animals prevents this

327 future directed behavior in humans. It is naive to think people in underdeveloped

328 countries would just assume the Western knowledge about adverse effects of fossil fuel

329 use to be true. They will not choose inefficient and expensive energy generation methods

330 over the easy energy provided by fossil fuels. Much has been written about leapfrogging

331 development. China could skip polluting stages of development and leap straight to

332 sustainable forms of energy production (Chen, 2004). China however, has large deposits

333 of coal. Without using this fossil fuel source for industrialization, China would never

334 have been able to grow so quickly in such a short time. As Dutch people say "it is hard to

335 imagine a windmill powering a steel construction factory". In fact, large scale steel

336 construction is necessary to build a windmill in the first place. Clearly, an educated

337 society is a requirement for gaining widespread support for pollution mitigation. Without

338 education, people are unable to see the need for it. This means that leapfrogging is

339 impossible. A country should go through a polluting stage of development before

340 cleaning up can take place.

342 4. Some techniques for the "pollute first, clean up later" strategy

343 As discussed, development seems to follow a predictable path. Industrialization is

344 initiated by investing capital in industry. Once underway, the rapid growth will give rise

345 to an efficient education system. The resulting well-informed society increases growth,

\footnotetext{
${ }^{5}$ Personal conversation of the first author with the farmers in Darab (Southwest Iran).
} 
346 and then realizes that its growth might not be sustainable. Consequently, efforts are made

347 to mitigate pollution while sustaining growth. This process has taken more than 100 years

348 for the first industrializing countries in the Western world. The Asian Tigers and China

349 have caught up in less than 50 years ${ }^{6}$. This double speed could be attained because the

350 Tigers and China only had to implement the latest Western technology, while the West

351 first had to invent every part of the process.

352 Pulverized-coal fired power plants, as in use in all developed countries, reach efficiency

353 levels of about $40 \%$ (Franco and Diaz, 2009). State of the art ultra-supercritical plants are

354 able to improve the efficiency around 50\%. A third technique known as Integrated

355 Gasifier Combined Cycle (IGCC) can operate at efficiency levels of 60\%. These

356 technologies can all be combined with modern carbon capture and sequestration (CCS)

357 technology, reducing $\mathrm{CO} 2$ emission to minimal amounts. These are examples of

358 technological advancements to enable the clean use of fossil fuel reserves. The main

359 problem with these technologies is their high costs and high complexity. Both of these

360 problems make them unsuitable for use in newly industrializing countries. They do

361 however clearly show great potential in sustaining development of the emerging BRIC

362 economies. If the Western world succeeds in profitably generating power from coal at

$36360 \%$ efficiency and with minimal greenhouse gas emission, the developed world will

364 dramatically reduce pollution, and will have completed their "clean up" process. This will

365 serve as an example for the Asian Tigers and the BRIC countries. A development model

366 could then be created to enable remaining undeveloped countries to catch up even faster

367 than China and the Tigers.

\footnotetext{
${ }^{6}$ China only lags behind the Asian Tigers in terms of GDP per capita because of the vast area of the country and the large, poor rural areas where development is still very low.
} 


\section{Setting the example, cleaning up the west}

369 The western world is the classical example for the developing world. While we are

370 worried about the environment, African youths are interested in getting coca-cola and

371 blue jeans. The Asian Tigers have modeled their education systems and industrial

372 methods after Western standards. By setting the right example, we can prevent growing

373 economies from making the same mistakes we did. By making technology available to

374 burn coal as efficiently and pollution free as possible, we can help development come in

375 as green a manner as possible.

376 In the West, efforts to mitigate pollution have widely become accepted. It is evident that

377 greening does not have to cost money. Every company is interested in cutting costs, as

378 lower costs increase profit, and cutting energy expenditure - for instance by replacing

379 light bulbs with LED illumination - is a great way to achieve this. Greening is a public

380 and corporate buzz so every new product with some green quality can easily get popular.

381 For the first time in history, a car's fuel economy and energy label is equally important a

382 decision criterion as the amount of horsepower or top speed. Nevertheless, errors have

383 been made. It is well known for example that it takes significantly more energy to create

384 a Toyota Prius (including the costs of research) than the amount of energy it will save

385 during its lifetime. In a striking 1992 article Robert Dean highlights some of these fads in

386 environmental policy. An interesting point is that burning waste, other than fossil fuel

387 derived waste such as oils and plastics, does not contribute to the greenhouse effect. The

388 reasoning is simple. The carbon contained in wood and wood derivatives such as paper

389 has been drawn out of the atmosphere during the growth of a tree or plant. Whether the

390 product is burned or left to decompose by nature, the carbon will be returned to the 
391 atmosphere a relatively short time after, it has been taken out. So, providing the global

392 forest and green vegetation area is sustained, burning wood or paper is a perfectly green

393 and sustainable way of energy $\operatorname{production}^{7}$. The west should strive to make greening

394 more of a means instead of an end in the near future. Constantly, making sure that green

395 initiatives are not costing more energy than they could save. Having said that, it is vital

396 that the West cuts back on their emission levels significantly to sustain the atmosphere

397 quality in the face of increasing emission by developing countries. The US and Europe

398 were responsible for $23.8 \%$ of global CO2 emission in 2007. China has already surpassed

399 the US at $21.5 \%$ of global CO2 emission (International Energy Agency, 2009). The quick

400 development of the Asian Tigers and subsequent rise of the Chinese and Indian

401 economies shows a highly effective development route. One study has shown that

402 Chinese $\mathrm{CO} 2$ emission levels have been doubled in the past five years. Moreover, even

403 by optimistic projections, Chinese emission levels will likely be more than double again

404 in the future (Guan et al., 2008). By that time, Chinese per capita emission levels will be

405 close to the American and European's levels. If Africa starts growing in a similar way as

406 Asian countries already have, global pollution levels will certainly reach outrageous

407 levels. Luckily in China, efforts to mitigate pollution have already started. Many

408 researchers, both domestic and foreign, are trying to devise ways of making Chinese

409 growth sustainable. It is eminent that these efforts are encouraged by the West and that as

410 much knowledge as possible is shared.

\footnotetext{
${ }^{7}$ Moreover, it is interesting to note a point made against the use of bio degradable plastics. Making plastics biodegradable frees the carbon contained in them to the atmosphere (thus, contributing to the greenhouse effect), while storing traditional inert plastics in a landfill puts the fossil carbon back into the ground where it came from.
} 
411 The task the western countries have in the $21^{\text {st }}$ century is twofold. First, the level at which

412 Western, Asian, Latin American and African pollution levels will ultimately converge

413 can largely be determined by mitigation strategies of the west. The technologically most

414 advanced countries should lead the way to ever greener forms of energy production and

415 waste management. Better use of nuclear energy in Europe for instance, could "free-up"

416 environment for cheap Indian coal installations to pollute (although one could argue that

417 the massive amounts of water vapor emitted by nuclear reactors could also pose a risk for

418 the climate). Nuclear power plants do not emit any $\mathrm{CO} 2$ or chemicals. The radioactive

419 waste can be easily disposed of with current technologies. Nuclear energy has all

420 potential to be a great sustainable power source. The only problem lies in the devastating

421 effects of nuclear weapons. The Western countries, most notably the USA, try to prevent

422 foreign nuclear activity (most recently Iran and North Korea) as much as possible. They

423 fear that nuclear technology would be used to construct weapons against their benefits.

424 This fear is most likely exaggerated. Nuclear war is a classical example of a problem with

425 no technical solution. In analogy with the game 'tic tac toe', it is blatantly obvious that

426 there can be no winners in an all out nuclear war.

427 Mitigation of household CO2 emission levels is important example setting behavior. It is

428 important that we discourage developing countries from attaining the same exorbitant

429 consumption levels we have today. The second task is making knowledge regarding

430 pollution control and greening available to the developing world. We should prevent

431 rising economies from making the same errors in recycling and greening attempts as we

432 have made. Best practices should be shared with the emerging BRIC economies and with 
433 the undeveloped areas in Latin America and Asia as well as with sub-Saharan African

434 countries.

\section{6. Discussion and conclusion}

437 It has become clear that the hypothesis of this paper is true. Polluting industries have

438 preceded greening in all cases. An uneducated population is unable to see why cleaning is

439 necessary to sustain life on earth. Moreover, green alternatives are simply too expensive

440 at this point to be of any use in developing countries. Pollute first, clean up later might at

441 this point be truly unavoidable.

442 It is possible however, to devise approaches to the sustainable application of this

443 development strategy. As it looks unlikely that industrial CO2 emission will cause

444 catastrophic climate change, there is no scientific objection against promoting the use of

445 fossil fuels in developing countries. As is evident from the histories of all highly

446 developed countries, the use of high energy fossil fuels is required to approach quick

447 development. It is possible, even likely, that green energy alternatives will eventually be

448 made efficient enough to be economically viable for use in poor countries, but at this

449 point in time, they are too expensive. However, if the clean up process starts soon enough,

450 the continued use of fossil fuels is not a big problem as it is commonly thought.

451 The success formula for development has been distilled from the development of the

452 Asian Tigers and China. These countries approached the Western levels of development

453 in less than half the time that the West needed for the same development level. The 'clean

454 up' process is well underway in those areas, now that the first rapid growth has been

455 realized. Given the proper guidance, the right knowledge and access to state of the art

456 technology, newly developing countries should be able to rush through the pollution 
457 stages at breakneck speed, reaching 'clean up' well before any problematic effects of 458 pollution can be expected to materialize. Seems that continuing mitigation strategies in 459 the West will free up environmental space for developing countries to pollute! Therefore, 460 the west should also set the example for developing countries by further reducing their 461 pollution levels.

462 A clear limitation in this paper is the neglect of political factors. China is still a subject to 463 censorship policies and is notorious for its violation of human rights. Also, Singapore 464 may have very high economic development and low poverty while characterized by an 465 abundance of regulation and government control. Political stress is of particularly 466 problematic proportions in sub-Saharan Africa. Political stability is a must have before 467 any significant development can take place. Moreover, it is highly preferable to have an 468 educated government. Hyper-inflation in Zimbabwe would not have to get so enormously 469 out of hand if the central bank would have been run by skilled economists for example. It 470 has been shown in China and Singapore that heavy state influence can positively affect 471 development, but ethical problems prevent promotion of these practices.

472 The Islamic world is a case in its own, which has been omitted from this paper. This area 473 is obviously troubled by political instability as well. The OPEC countries may be rich, 474 but some have extreme differences between rich and poor and other disabling problems 475 such as women oppression practices. Iran, as the most emerging and influential economy 476 in the Middle East for example, is also a current hot subject to censorship policies and 477 notorious for its human rights violation. It is clear that political factors are important. 478 They were however not included in the delimitation of this study. If the prerequisite of a 479 stable political situation is met, the theories in this paper can be held. 
480 Finally, some implications for future studies could be perceived as a result of this study.

481 In theory, a critical review could be drawn on this study portraying a historical overview

482 on 'development economic theories'. Such an overview can scrutinize how novel the

483 hypothesis of this study is and whether it could be discussed in the frame of previously

484 formulated development economic theories or can be considered as a new incubator for

485 the future theories. In practice, a multi-case study could be conducted to tentatively test

486 whether the hypothesis is workable. Such case studies could be held on the bases of both

487 'country-case' (e.g. BRIC countries) and 'region-case' (e.g. the Middle East and 488 Southeast Asia).

490 References

491 Asimov, I., Pohl, F., 1993. Our Angry Earth. Tor Books.

492 Bucha, V., 1991. Possible causes of enhanced greenhouse effect as due to natural and 493 anthropogenic factors. Adv. Space Res. II, 55-60.

494 Chen, Y., Farinelli, U., Johansson, T.B., 2004. Technological leapfrogging - a strategical 495 pathway to modernisation of the Chinese iron and steel industry? Energy for $496 \quad$ Sustainable Development 8, 30-38.

497 Colclough, C., 1982. The impact of primary schooling on development: a review of the $498 \quad$ evidence. World Development 10, 167-185.

499 Dean, R.B., 1995. Environmental fads and fallacies. Waste Management \& Research 13, $500 \quad 201-206$.

501 IPCC (Intergovernmental Panel on Climate Change), 2001. In: Houghton, J.T., et al. 502 (Eds.). Cambridge Univ. Press, New York. 
503 IPCC (Intergovernmental Panel on Climate Change), 2007. The physical science.

504 Ganzeboom, H.B.G., Nieuwbeerta, P., 1999. Access to education in six Eastern European

505 countries between 1940 and 1985. Results of a cross-national survey. Communist

506 and Post-Communist Studies 32, 339-357.

507 Gilliland, R.L., 1982. Solar, volcanic, and C02 forcing of recent climatic changes.

$508 \quad$ Climatic Change 4, 111-131.

509 Gladwell, M., 2008. Outliers. Little, Brown and Company.

510 Guan, D., Hubacek, K., Weber, C.L., Peters, G.P., Reiner, D.M., 2008. The drivers of

511 Chinese CO2 emissions from 1980 to 2030. Global Environmental Change 18, $512 \quad 626-634$.

513 Hansen, J. E. et al., 1981. Climate impact of increasing atmospheric carbon dioxide. $514 \quad$ Science 213, 957-966.

515 Heinink, A.L., Koetsier, J.M.B., 1984. Onderwijs in de derde wereld. Hefboom voor 516 ontwikkeling? Informatiebladen van het instituut voor Onderwijskunde 15, 73- 86.

517 Jones, P.D., New, M., Parker, D.E., Martin, S., Rigor, I.C., 1999. Surface air temperature 518 and its changes over the past 150 years. Reviews of Geophysics 37, 173-199.

519 Lin, T.C., 2004. The role of higher education in economic development: an empirical 520 study of Taiwan case. Journal of Asian Economics 15, 355-371.

521 Lin, T.C., 2003. Education, technical progress, and economic growth: the case of Taiwan. 522 Economics of Education Review 22, 213-220.

523 Little, A.W., Green, A., 2009. Successful globalisation, education and sustainable 524 development. International Journal of Educational Development 29, 166-174. 
525 Lloyd, C.B., Kaufman, C.E., Hewett, P., 2000. The spread of primary schooling in sub-

526 Saharan Africa: implications for fertility change. Population and Development $527 \quad$ Review 26, $483-515$.

528 Lomborg, B. The Skeptical Environmentalist (Cambridge University Press, 2001).

529 Manderscheid, R. Burkart, S., Bramm, A., Weigel, H., 2003. Effect of CO2 enrichment

530 on growth and daily radiation use efficiency of wheat in relation to temperature and

531 growth stage. Europ. J. Agronomy 19, 411-425.

532 Parker, D.E., Jones, P.D., Bevan, A., Folland, C.K., 1994. Interdecadal changes of 533 surface temperature since the late $19^{\text {th }}$ century. Journal of Geophysical Research 99 , $534 \quad 14373-14399$.

535 Plambeck, E.L., Hope, C., Anderson, J., 1997. The page 95 model: integrating the science 536 and economics of global warming. Energy Economics 19, 77-101.

537 Prior, S.A., Rogers, H.H., Runion, G.B., Mauney, J.R., 1994. Effects of free air CO2 538 enrichment on cotton root growth. Agricultural and Forest Meteorology 70, 69-86.

539 Qian, C., 2009. Constructing a new disciplinary framework of modern world history 540 around the theme of modernization. Chinese Studies in History 42, 7-24.

541 Song, C., 2006. Global challenges and strategies for control, conversion and utilization of $542 \mathrm{CO} 2$ for sustainable development involving energy, catalysis, adsorption and 543 chemical processing. Catalysis Today 115, 2-32.

544 Szirmai, A., 2005. The Dynamics of Socio-Economic Development. Cambridge $545 \quad$ University Press. 
546 Wolf, J., Van Oijen, M., 2003. Model simulation of effects of changes in climate and

547 atmospheric $\mathrm{CO} 2$ and $\mathrm{O} 3$ on tuber yield potential of potato (cv. Bintje) in the

548 European Union. Agriculture, Ecosystems and Environment 94, 141-157. 